Classification

Physics Abstracts

$07.80-73.00-78.00$

\title{
Investigation of metal cluster layers by EELS
}

\author{
Hellmut Seiler $\left({ }^{1}\right)$, Ulrich Haas $\left({ }^{1}\right)$, Karl-Heinz Körtje $\left({ }^{2}\right)$ and Bernd Ocker $\left({ }^{1}\right)$ \\ (1) Institut für Physik, Universität Hohenheim, D-7000 Stuttgart-70, Germany \\ $\left(^{2}\right)$ Institut für Zoologie, Universität Hohenheim, Garbenstr. 30, D-7000 Stuttgart-70, Germany
}

(Received September 13, 1990; accepted March 26, 1991)

\begin{abstract}
The physical properties of small metal particles reveal an intermediate position between atomic and bulk material. Especially $\mathrm{Ag}$ has shown pronounced size effects. We compared homogeneous silver layers with cluster layers of small silver particles with diameters of about $50 \mathrm{~nm}$ deposited on thin Pioloform foils, respectively. The EELS spectra of the particles seem to be different in the low loss region from the spectra of homogeneous Ag layers. This can be attributed to the influence of the carbon foil and the packing density of the particles. Investigations of Sn particles on Pioloform foils were performed to obtain additional information. Furthermore, we studied the optical behavior of different layers of $\mathrm{Ag}$ by Photoacoustic Spectroscopy. For particles, the plasma resonance of conduction electrons gives rise to an absorption peak, which shifts towards longer wavelengths for increasing packing density.
\end{abstract}

\section{Introduction.}

The investigation of small metal particles is of considerable interest for technical applications, e.g., for heterogeneous catalysis and also of significance for fundamental physical problems. Small particles or clusters reveal an intermediate position between atomic and bulk material. Many physical properties change with decreasing size of the particles: Silver has shown pronounced size effects as demonstrated, e.g., by surface enhanced Raman scattering [1], infrared absorption [2,3] and photo electron emission [4-7]. The resistivity of small indium particles increases by six orders of magnitude when the particle size is reduced from $1 \mu \mathrm{m}$ to $10 \mathrm{~nm}[8,9]$. The investigation of small $\mathrm{Au}$ clusters by photo electron spectroscopy shows, that the valence band broadens with growing crystallite size [10]. The Auger peak of $\mathrm{Cu}$ shifts due to a change in the valence band and core levels as the cluster size decreases [11].

Particle size effects concerning the conduction electrons can be detected by optical methods as well as by EELS in the low energy region $[12,13]$.

The influence of particle size on many of the optical properties can be described by the theory of Mie [14] and was investigated by optical and infrared absorption $[3,13]$ as well as by photothermal and photoacoustic spectroscopy [15-17]. The size and the shape of small particles were imaged by high resolution TEM, SEM and STEM [18-22]. The local chemical and electronic properties of small particles were investigated by EELS and image energy filtering in a STEM [23-27]. For small 
particles most of the work with EELS has been devoted to plasmon excitations, i.e. the excitation of collective oscillations of the quasi-free electron gas in metals as shown for instance for $\mathrm{Al}, \mathrm{Ga}$ and $\mathrm{Sn}$ [23]. The energy of plasmons is proportional to the square root of the density of valence electrons. A decrease of plasmon energy can be explained by a decrease of the electron density. Especially the generation of volume and surface plasmons of supported Al particles in ultra high vacuum were investigated [24-27]. In studying plasmon excitations of small particles by means of EELS, the effect of the supporting film substrate has to be taken into account, however [27-28].

\section{Experimental results and discussion.}

Silver: We prepared silver layers evaporated in high vacuum and cluster layers of small silver particles, evaporated in $\mathrm{N}_{2}$ at a pressure of about $10^{2} \mathrm{~Pa}$, deposited on thin Pioloform foils, respectively. The Ag layers produced in the inert gas atmosphere are close-packed smoke particles looking as dark as soot, whereas the silver layers evaporated in high vacuum burnish bright. The investigations were performed by electron optical methods (TEM, SEM, EELS) and by Photoacoustic (PA) Spectroscopy (gas-microphone detection). The observation of cluster layers with TEM and high resolution SEM shows small silver particles with diameters of about $50 \mathrm{~nm}$ (Fig. 1

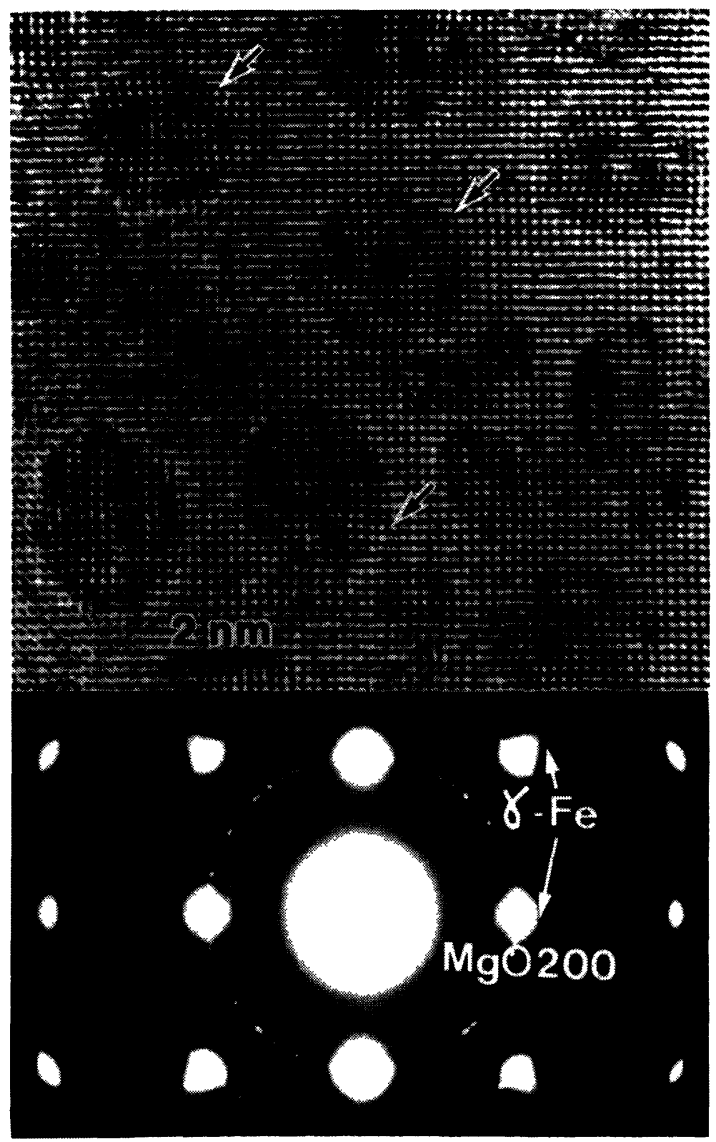

Fig. 1. - TEM micrograph of Ag particles (brightfield). 
and Fig. 2, respectively). The electron diffraction patterns of homogeneous Ag layers and of cluster layers are similar. The EELS spectra were measured with TEM (Zeiss EM 902) at $80 \mathrm{keV}$, a magnification of 20000 or higher (thus obtaining averaged information of several particles on a definite area of the Pioloform foil) and an aperture of $30 \mu \mathrm{m}$. The EELS spectra in the low loss region of the $\mathrm{Ag}$ particles and of the homogeneous $\mathrm{Ag}$ layer seem to be quite different [29].

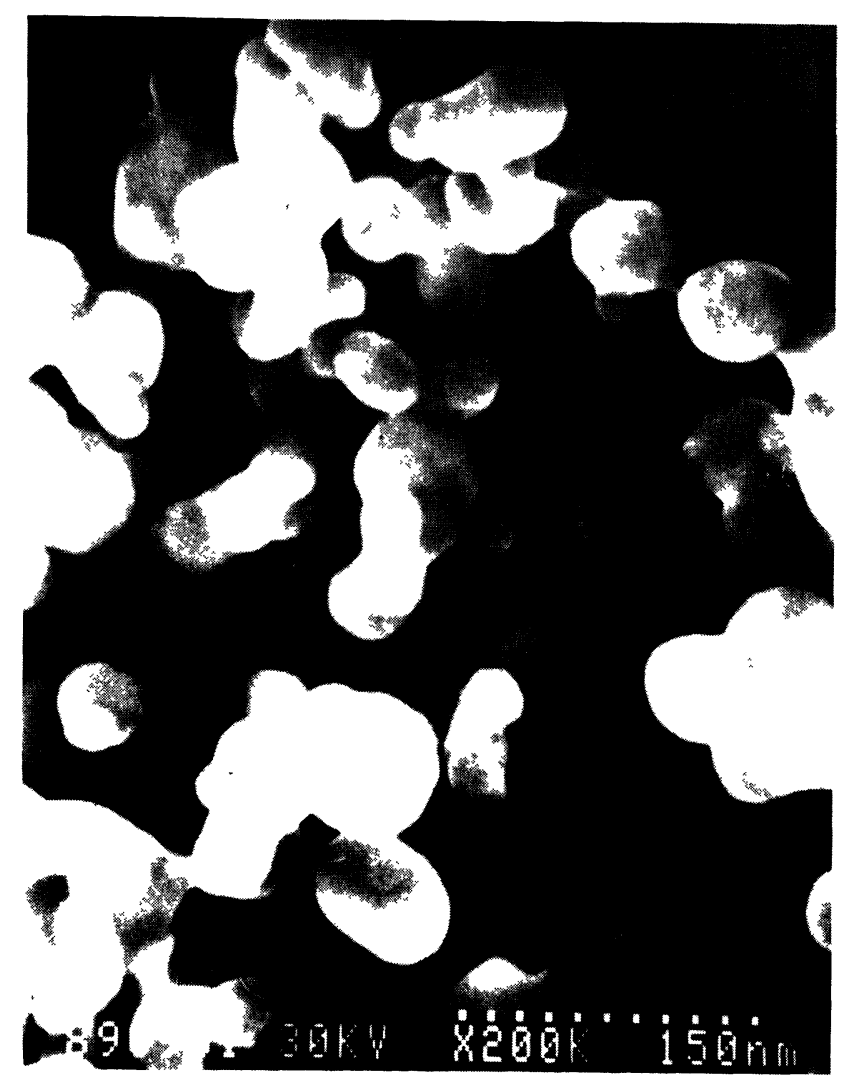

Fig. 2. - High resolution SEM micrograph of Ag particles.

The different shape of the spectra can be attributed to the influence of the carbon foil and the packing density of the Ag. This is shown in figure 3 (top). Assume that we have a homogeneous Ag layer of about $80 \mathrm{~nm}$ on a Pioloform foil with a thickness of $30 \mathrm{~nm}$. Evaporating the same amount of $\mathrm{Ag}$ in an inert gas atmosphere of about $10^{2} \mathrm{~Pa}$ we obtain small particles on the foil with a certain packing density. We have parts of the foil where the electron beam only interacts with the Pioloform foil and other parts where the electron beam interacts with $\mathrm{Ag}$ of different thickness. Great thickness may cause e.g., multiple excitation of plasmon losses.

In order to avoid interferences in the spectra of $\mathrm{Ag}$ and Pioloform, we investigated self-supporting Ag layers (Fig. 3a, Fig. 4) and pure Pioloform foils (Fig. 3b, Fig. 5) and foils with a low packing density of the particles (Fig. 3c, Fig. 7). To investigate the low loss spectra of the particles only, one possibility to reduce the influence of the carbon foil is to increase the magnification of TEM to have only one particle under investigation. In this case the probability of multiple excitation 

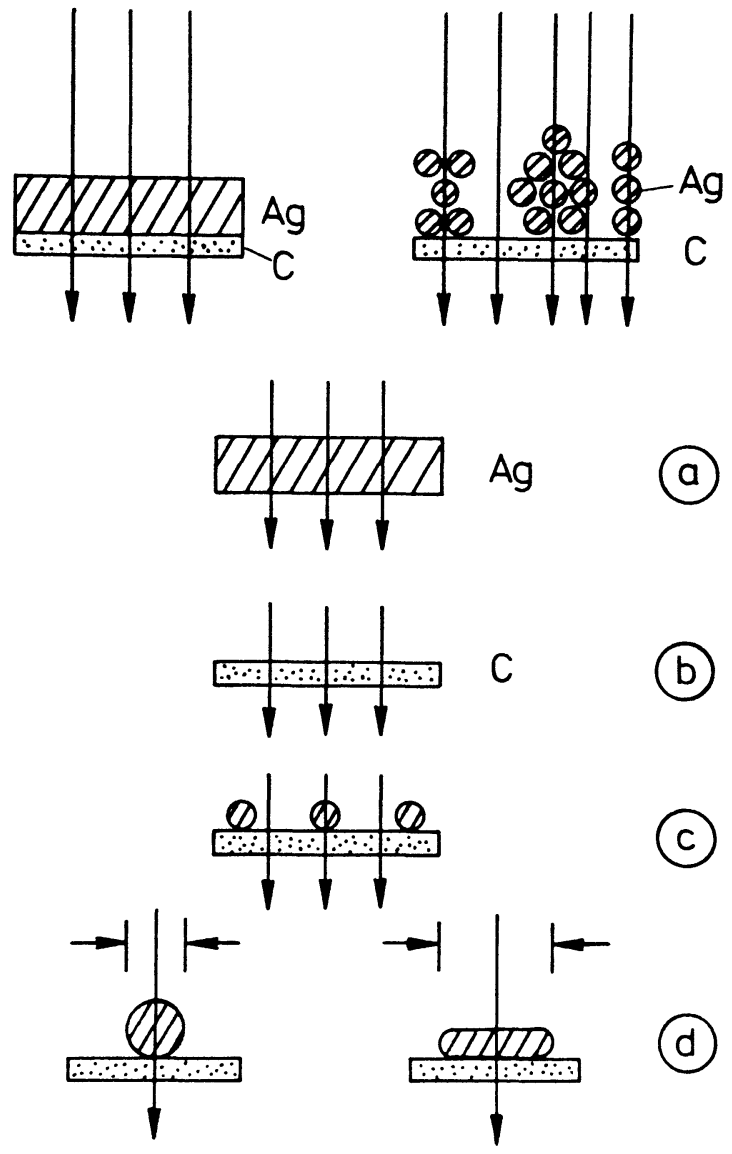

Fig. 3. - Schematic drawing of the investigated objects: Homogeneous Ag layer on Pioloform foil (top, left) and Cluster Ag layer on Pioloform foil (top, right): a) Ag foil, self -supporting; b) Pioloform foil; c) Pioloform foil with Ag clusters, low packing density; d) Single particles with different shape (high magnification).

depends on the shape of the particle (Fig. 3d). The EELS spectra of the low loss region and of the edge structure of the high loss region are discussed in the following. The self-supporting Ag foil (Fig. 4, top) shows in the low loss region a main maximum at $25 \mathrm{eV}$ and besides the first sharp loss at $4 \mathrm{eV}$ there are broader losses at $8 \mathrm{eV}, 18 \mathrm{eV}$ and $33 \mathrm{eV}$. The Pioloform foil, mainly carbon as indicated by the edge structure (Fig. 5, bottom) reveals a main maximum at $23 \mathrm{eV}$ and a weak maximum at $6 \mathrm{eV}$ (Fig. 5, top). A thin homogeneous Ag layer (about $40 \mathrm{~nm}$ ) on a Pioloform foil (Fig. 6) shows an overlap of the main carbon and main $\mathrm{Ag}$ peak and two small $\mathrm{Ag}$ peaks at $4 \mathrm{eV}$ and $8 \mathrm{eV}$. According to Raether [12] the interband transition of $\mathrm{Ag}$ is expected at $3.9 \mathrm{eV}$, the volume plasmon loss at $3.7 \mathrm{eV}$ and the surface plasmon loss at $3.6 \mathrm{eV}$, which cannot be separated here. Figure 7 and figure 8 demonstrate the low loss region and the $\mathrm{M}_{4,5}$ edge structure of $\mathrm{Ag}$ particles with different packing densities. For a low packing density we see the main peak of carbon in the low loss region and maxima at about $4 \mathrm{eV}$ and $8 \mathrm{eV}$ of $\mathrm{Ag}$. The $\mathrm{C}$ and $\mathrm{Ag}$ edges are clearly to be seen. The spectrum of the Ag particles with higher packing density (Fig. 8) shows mainly the structure of the pure $\mathrm{Ag}$ foil, with main peaks at $4 \mathrm{eV}, 8 \mathrm{eV}$ and $25 \mathrm{eV}$. The $\mathrm{M}_{4,5}$ edge of $\mathrm{Ag}$ is so weak that an identification of $\mathrm{Ag}$ is difficult. The main difference between the low loss spectra of 

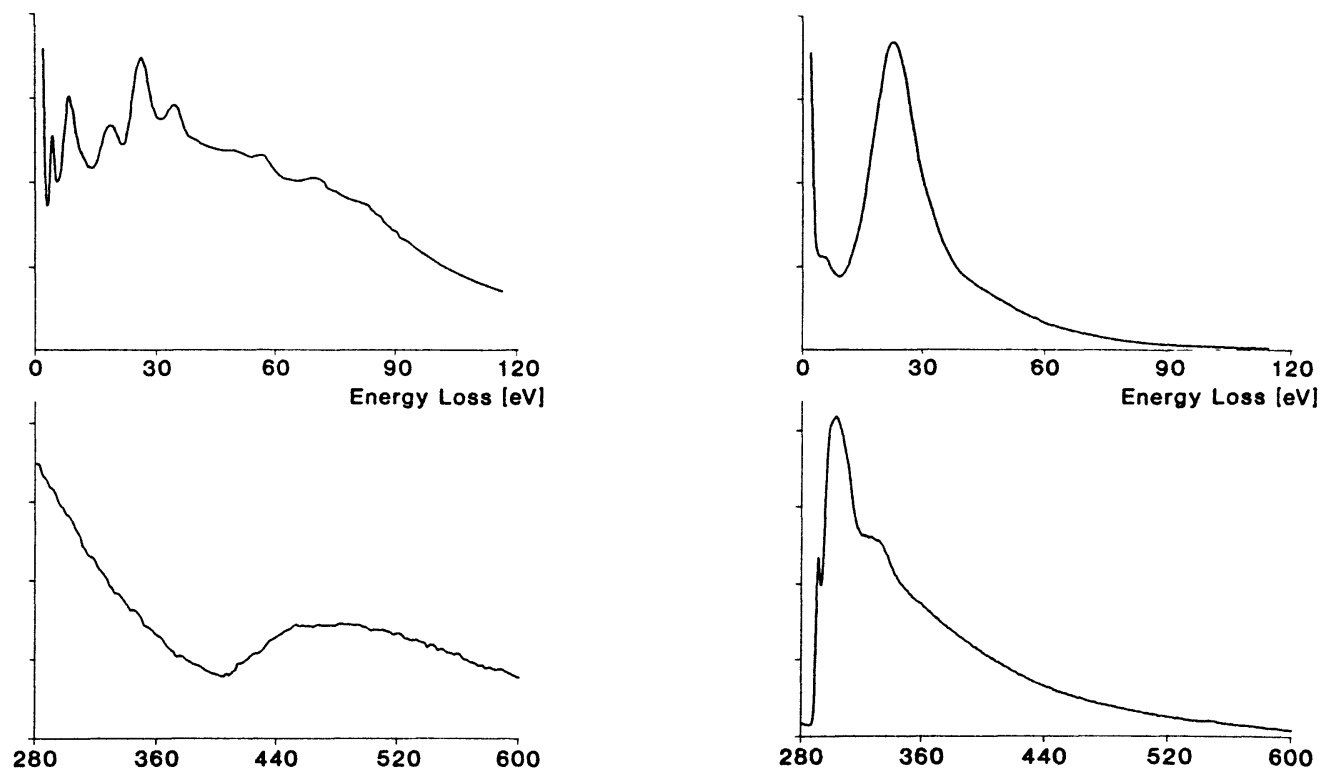

Fig.4.

Fig.5.

Fig. 4. - EELS spectrum of a self-supporting Ag foil in the low energy region (top) and the edge structure (bottom).

Fig. 5. - EELS spectrum of a Pioloform foil.

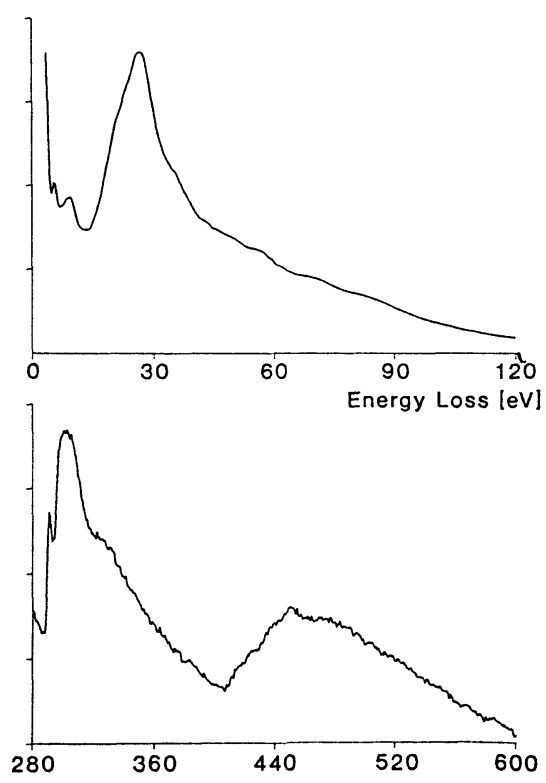

Fig.6.

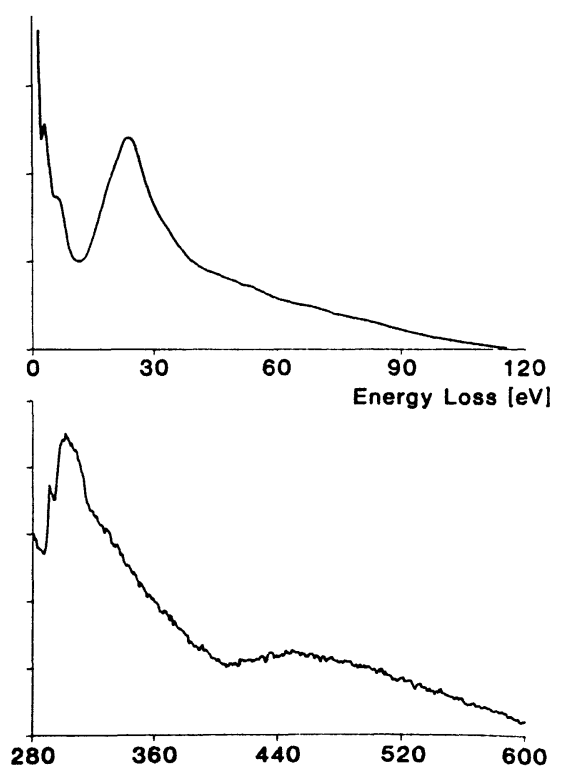

Fig.7.

Fig. 6. - EELS spectrum of a homogeneous Ag layer on Pioloform foil.

Fig. 7. - EELS spectrum of Ag particles, low packing density. 

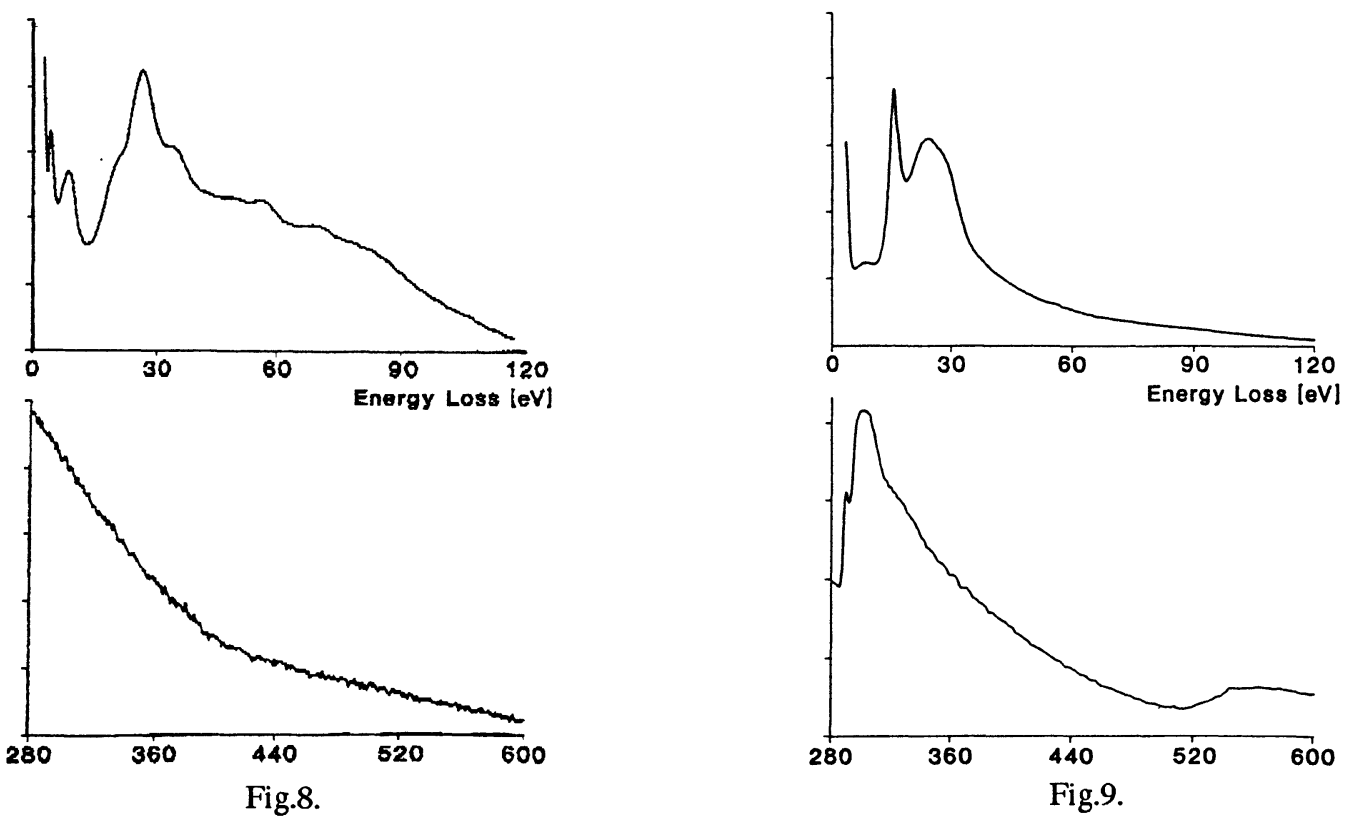

Fig. 8. - EELS spectrum of Ag particles, high packing density.

Fig. 9. - EELS spectrum of Sn particles.

a compact layer and a layer of small particles of $\mathrm{Ag}$ can be explained by an overlap of the spectra of $\mathrm{C}$ and of $\mathrm{Ag}$ with different thickness. A comparison proves that the peaks at $4 \mathrm{eV}$ and $8 \mathrm{eV}$ of $\mathrm{Ag}$ seem to be shifted to lower energies with decreasing packing density of the particles.

Ouyang et al. [30] investigated the surface plasmon loss of small $\mathrm{Ag}$ particles at about $3.5 \mathrm{eV}$ with high spatial and energy resolution STEM. For particles with diameters ranging from 10 to $20 \mathrm{~nm}$, the surface plasmon energy was found to decreasing with decreases of particle size, too. A dependence of the energy of low energy loss spectra can also be attributed to a chemical change of surface or to the strong dependence of surface plasmon excitation on the local geometry of the particles [27].

In order to avoid an overlap of the main carbon peak and a loss peak of $\mathrm{Ag}$ we investigated $\mathrm{Sn}$ particles, too.

Tin: The Ag particles are generated by gas aggregation technique. Sn evaporated in high vacuum on a pioloform foil gives single crystal particles by agglomeration. The particles are shown in figure 10. For $\mathrm{Sn}$ the main plasmon loss at $14 \mathrm{eV}$ is clearly separated from the main peak of the carbon foil at $23 \mathrm{eV}$ (Fig. 9). Thus, spectroscopic imaging is possible. Figure 10 a shows the $\mathrm{Sn}$ particles in TEM zero loss image mode, whereas in figure $10 \mathrm{~b}$ the particles are imaged with $\mathrm{Sn}$-loss at $14 \mathrm{eV}$ and in figure $10 \mathrm{c}$ with C-loss at $23 \mathrm{eV}$. Increasing the magnification up to 140000 it is possible to investigate one single $\mathrm{Sn}$ particle (these particles were generated in an inert gas atmosphere of about $10^{2} \mathrm{~Pa}$ ). Figure 11 shows multiple excitation of the plasmon loss at $14 \mathrm{eV}$ in the low loss region. At this magnification the edge structure is rather noisy. 


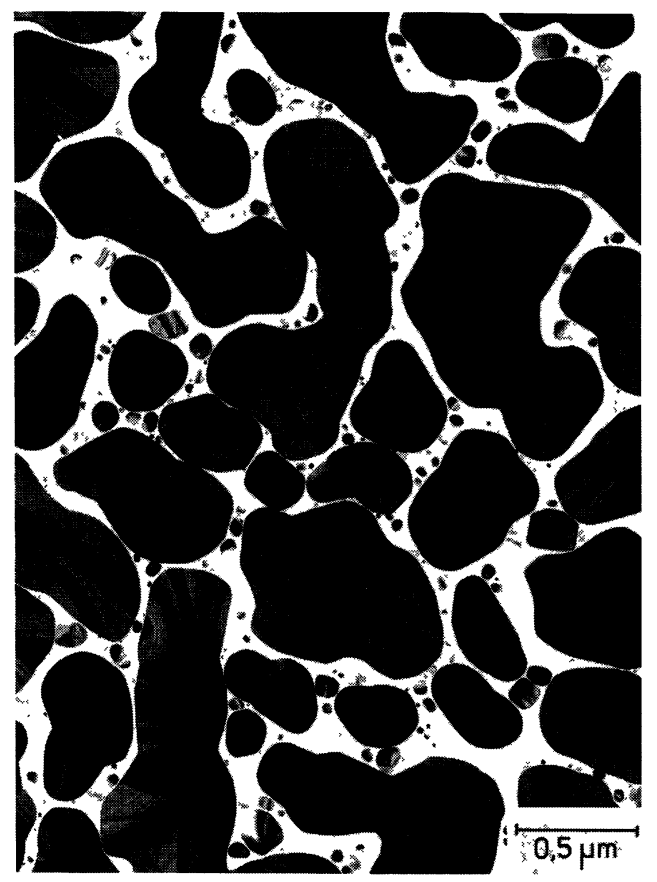

(a)

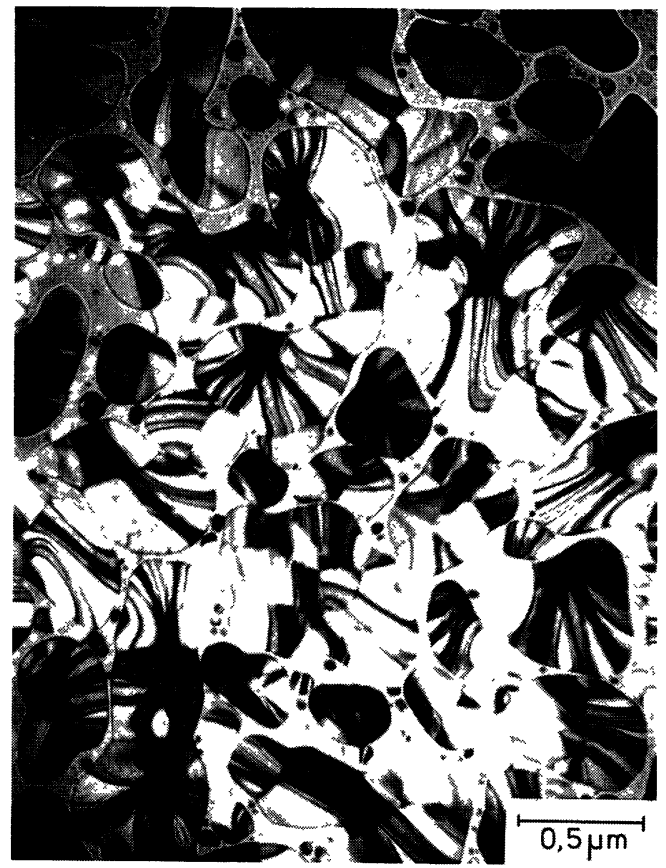

(b)

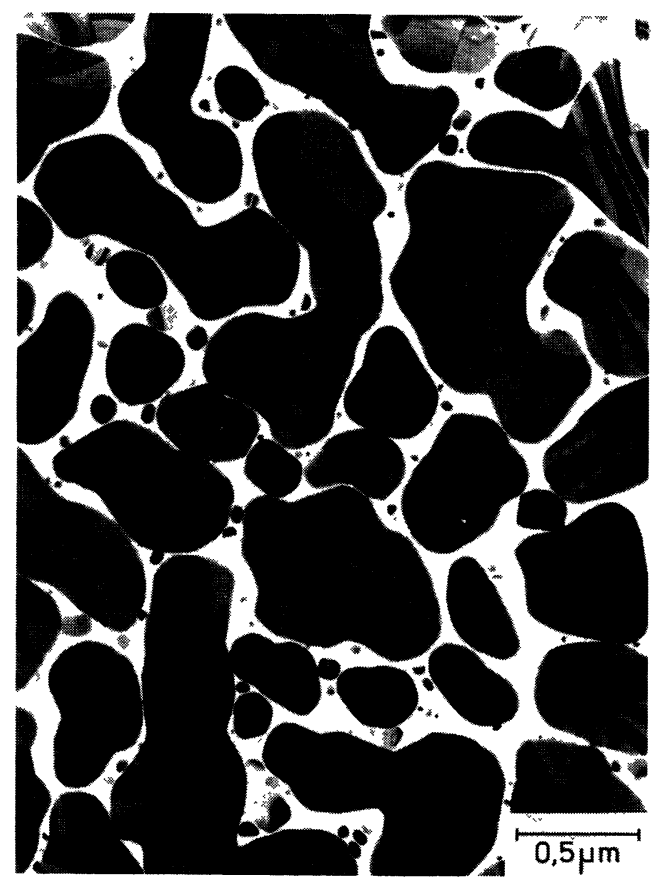

(c)

Fig. 10. - Sn particles imaged in TEM: a) zero loss; b) electron spectroscopic image with an electron loss of $14 \mathrm{eV}(\mathrm{Sn}): \Delta E=2 \mathrm{eV} ; \mathrm{c}$ ) electron spectroscopic image with an electron loss of $23 \mathrm{eV}(\mathrm{C}) ; \Delta E=2 \mathrm{eV}$. 


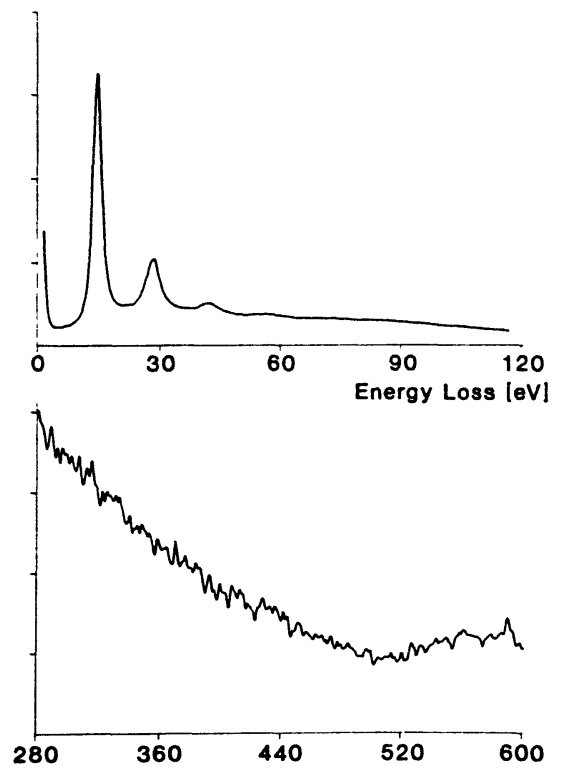

Fig. 11. - EELS spectrum of one single Sn particle.

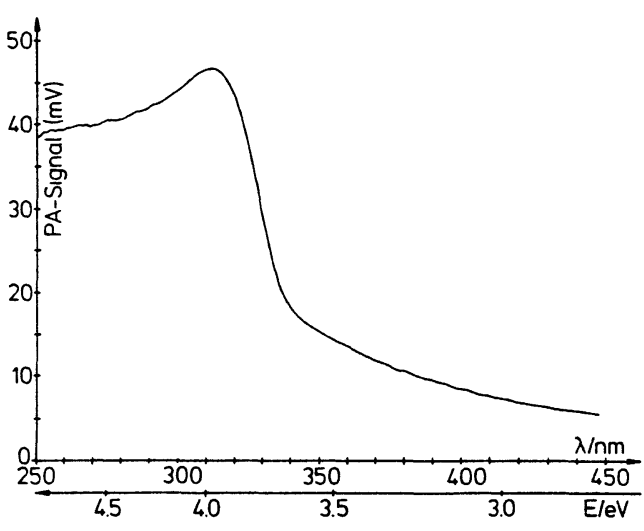

Fig.12.
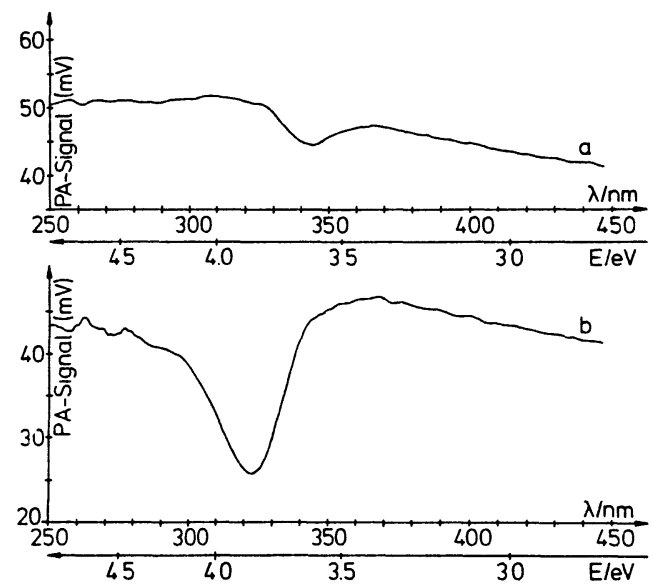

Fig.13.

Fig. 12. - Photoacoustic spectrum in the UV/VIS of a homogeneous Ag layer on quartz.

Fig. 13. - Photoacoustic spectra of Ag particles: a) high packing density; b) low packing density. 


\section{Optical investigations.}

We studied the optical absorption behavior of homogeneous silver layers and small silver particle systems on quartz supports by PA-spectroscopy in the UV/VIS range from $250 \mathrm{~nm}$ to $450 \mathrm{~nm}$. Spectra of the $\mathrm{Ag}$ layers evaporated in high vacuum show in the UV spectral region the well known change of absorptivity due to an interband transition of bare silver (Fig. 12). The absorption behavior of the cluster layers differs in this energy region, however, and changes obviously for decreasing packing density of the small silver particles. Figure 13a shows the PA-signal of cluster layers with different packing densities (for Fig. 13a twice as for Fig. 13b). Whereas only a smooth change of the absorption is observed in figure 13a, a distinct signal is obtained for lower packing densities. The maximum of the cluster layer spectrum at about $365 \mathrm{~nm}$ is absent from the absorption curve of a homogeneous silver layer (Fig. 12) but the spectrum is similar to the results for a statistically roughened bare surface of silver as well as for small $\mathrm{Ag}$ particles embedded in a dielectric matrix with low packing density $[12,31]$. This absorption peak is the well known plasma resonance of the conduction electrons of $\mathrm{Ag}$ and is induced by the topological structure of the cluster layers composed of small silver particles (islands of spheres of Ag with a diameter $d \ll \lambda$, where $\lambda$ is the wavelength of the exciting light). The maximum of this peak reveals a shift to longer wavelengths for increasing packing density of the particles, in accordance with results of optical absorption spectra of Ag microcrystals [32].

\section{Summary.}

The investigation of small particles by EELS in the low energy region is an important tool for the probing of electronic states. However, the particles are mostly supported on thin film substrates. Therefore, the contribution of the substrate to the spectra of the particles in the low loss region must be taken into consideration. The excitation of interband transition, volume and surface plasmons of Ag normally cannot be separated by EELS. For particles, there is an indication of a shift of the peaks of $\mathrm{Ag}$ at $4 \mathrm{eV}$ and $8 \mathrm{eV}$ to lower energies with decreasing packing density. This will be subject to further investigations.

The application of photons to excite surface plasmons of metallic particles is demonstrated by photoacoustic spectroscopy. A shift of the plasma resonance to lower wavelengths with increasing packing density of $\mathrm{Ag}$ particles is observed.

Moreover, it may be of interest that EELS spectra are often clearly distinct in the low energy region for objects which are too thick for material analysis by the edge structure, especially at high magnification.

\section{Acknowledgements.}

The authors thank Prof. Dr. M. Müller (ETH, Zürich) for the picture of Ag particles in HRSEM. The financial support of the Deutsche Forschungsgemeinschaft is gratefully acknowledged. 


\section{References}

[1] SiIman O., Bumm L.A., Callaghan R., BlatchFord C.G. and KeRKer M., Surface-Enhanced Raman Scatttering by Citrate on Colloidal Silver, J. Phys. Chem. 87 (1983) 1014-1023.

[2] DEVATY R.P. and SIEVERS A.J., Far-Infrared Absorption by Small Metal Particles, Phys. Rev. Lett. 52 (1984) 1344-1347.

[3] HALPERIN W.P., Quantum size effects in metal particles, Rev. Mod. Phys. 58 (1986) 533-606.

[4] SCHMIDT-OTT A., SCHURTENBERGER P. and SiEgMANN H.C., Enormous Yield of Photoelectrons from Small Particles, Phys. Rev. Lett. 45 (1980) 1284-1287.

[5] Burtscher H., Schmidt-Ott A. and Siegmann H.C., Photoelectron Yield of Small Silver and Gold Particles Suspended in Gas up to a Photon Energy of $10 \mathrm{eV}$, Z. Phys. B - Cond. Matt. 56 (1984) 197-199.

[6] EKARDT W., Size-dependent photoabsorption and photoemission of small metal particles, Phys. Rev. B31 (1985) 6360-6370.

[7] MÜlLER U., SCHMIDT-OTT A. and BURTSCHER H., Photoelectric quantum yield of free silver particles near threshold Z. Phys. B - Cond. Matt. 73 (1988) 103-106.

[8] MARQUARDT P., NimTZ G. and MÜHLSChlegel B., On the Quasi-Static Conductivity of SubMicrometer Crystals, Solid State Commun. 65 (1988) 539-542.

[9] MARQUARDT P. and NIMTZ G., On Electron Confinement Effects and the Ultimate Size Reduction in Semiconductor Devices, Semicond. Sci. Technol. 2 (1987) 833-834.

[10] CORDES O. and HARSDORFF M., Investigation of Gold Clusters with Photoelectron Spectroscopy, Appl. Surf. Sci. 33/34 (1988) 152-159.

[11] CResCenzi M. De, DiociaiUti M., LozZi L., Picozzi P., SANTUCCI S., BatTistoni C. and MatTogno G., Size Effects on the Linewidths of the Auger Spectra of Cu Clusters, Surf. Sci. 178 (1986) 282289.

[12] RAETHER H., Surface Plasmons on Smooth and Rough Surfaces and on Gratings, Springer Tracts Mod. Phys. 11 (1988).

[13] KReIBIG U. and GenZel L., Optical Absorption of Small Metallic Particles, Surf. Sci. 156 (1985) 678700.

[14] MIE G., Beiträge zur Optik trüber Medien, speziell kolloidaler Metallosungen, Ann. Phys. 25 (1908) 377-445.

[15] BAUER M. and BREUER H.D., Photothermal Investigations on Small Silver Particles, Springer Series Opt. Sci. 58 (1988), P. Hess and J. Pelzl Eds. Photoacoustic and Photothermal Phenomena pp. 214216.

[16] InAGaKi T., Gourdonnet J.P. and ARAKaWA E.T., Photoacoustic Studies of Surface Plasmons in Metallic Microstructures, Springer Series Opt. Sci. 58 (1988), P. Hess and J. Pelzl Eds. Photoacoustic and Photothermal Phenomena, pp. 156-163.

[17] HAAS U. and SEILER H., Untersuchung homogener und poröser Silberschichten mittels optischer und elektronenoptischer Methoden. Beitr. Elektronenmikroskop, Direktabb. Oberfl 22 (1989) 295-300.

[18] MARKS L.D., Imaging Small Particles, Uttramicroscopy 18 (1985) 445-452.

[19] HOWIE A. and MILNE R.H., Excitations at Interfaces and Small Particles, Ultramicrosc. 18 (1985) 427434.

[20] Colliex C., MAURICE J.L. and UGaRTE D., Frontiers of Analytical Electron Microscopy with Special Reference to Cluster and Interface Problems, Ultramicroscopy 29 (1989) 31-43.

[21] LIU J. and COWLEY J.M., High Resolution Electron Imaging in a STEM, Scanning Micr. 2(1988) 65-81.

[22] SaIto Y., TAKemoto A., TANAKA N. and Mihama K., Fine particles of icosahedral Al-Mn alloy produced by gas evaporation technique, Proc. XI ${ }^{\text {th }}$ Int. Congr. Electr. Micr. I (1986) pp. 169-170.

[23] UgARTE D. and COLLIEX C., Investigation of Local Chemical and Electronic Properties of Small Particles with EELS Point Analysis and Image Energy Filtering in a STEM, Z. Phys. 12 (1989) 333-339.

[24] Crescenzi M. De, PicozZi P., SANTUOCi S., Battistoni C. and MatTogno G., Cluster Growth of Cu on Graphite: XPS, Auger and Electron Energy Loss Studies. Solid State Comm. 51 (1984) 811-815.

[25] BATSON P.E., Inelastic Scattering of Fast Electrons in Clusters of Small Spheres, Surf. Sci. 156 (1985) $720-734$.

[26] ACHÈVe M., Colliex C., KoHL H., NourTier A. and Trebbia P., Theoretical and experimental study of plasmon excitations in small metallic spheres, Ultramicroscopy 20 (1986) 99-106.

[27] WANG Z.L. and CowLEY J.M., Surface Plasmon Excitation for Supported Metal Particles, Ultramicroscopy 21, (1987) 77-94, 347-366. 
[28] OUYANG F. and IsaAcSON M., Accurate Modeling of Particle-Substrate Coupling of Surface Plasmon Excitation in EELS, Ultramicrosc. 31 (1989) 345-350.

[29] SEILER H., HAAS U. and KÖRTJE K.H., Investigation of Cluster Layers of Small Metal Particles by TEM, SEM, EELS and by Photoacoustic Spectroscopy, Proc. of the $\mathrm{XII}^{\text {th }}$ Int. Congr. Electr. Micr. I (1990) pp. 250-251.

[30] OUYANG F., BATSON P.E., and ISAACSON M., Study of surface plasmon excitation of nanometer size metallic particles in STEM. Proc. XII th Int. Congr. Electr. Microsc. I (1990) pp. 274-275.

[31] KREIBIG U., SCHMITZ B. and BREUER H.D., Separation of plasmon polariton modes in small metal particles, Springer Series Opt. Sc. 58 (1988), P. Hess and J. Pelzl Eds.Photoacoustic and photothermal phenomena, pp. 217-219.

[32] ABE H., SCHULZE W. and TESCHE B., Optical properties of silver microcrystals prepared by means of the gas aggregation technique, Chem. Phys. 47 (1980) 95-104. 